\title{
Treatment outcomes of gonadotropin-releasing hormone agonist in obese girls with central precocious puberty
}

Hye Ryun Kim, MD, Hyo-Kyoung Nam, MD, PhD, Young-Jun Rhie, MD, PhD, Kee-Hyoung Lee, MD, PhD

Department of Pediatrics, Korea University College of Medicine, Seoul, Korea
Received: 7 June, 2017

Revised: 1 September, 2017

Accepted: 19 September, 2017

Address for correspondence:

Kee-Hyoung Lee, MD, PhD

Department of Pediatrics, Korea University College of Medicine, 73 Inchon-ro, Seongbuk-gu, Seoul 02841, Korea

Tel: $+82-2-920-6604$

Fax: +82-2-922-7476

E-mail:khlee218@kumc.or.kr

https://orcid.org/0000-0002-43199019
Purpose: This study investigated the influence of obesity on the clinical course and effect of gonadotropin-releasing hormone analog $(\mathrm{GnRHa})$ treatment in girls with central precocious puberty (CPP).

Methods: Medical records of 182 girls with CPP treated with GnRHa were reviewed. They were divided into 2 groups: normal weight $(n=108)$ and overweight/obesity $(n=74)$. Chronological age (CA), bone age (BA), difference between BA and CA (BA$(\mathrm{CA})$, standard deviation score (SDS) of height, body mass index (BMI), predicted adult height $(\mathrm{PAH})$, and laboratory findings were compared at baseline, after 1 year, and at the end of GnRHa treatment in both groups.

Results: Mean BMI SDS at baseline was $0.08 \pm 0.60$ in the normal weight group and $1.55 \pm 0.36$ in the overweight/obesity group. Initial CA, BA, midparental height, and PAH were similar between the 2 groups. BA-CA after treatment was significantly decreased compared to baseline in both groups $(P<0.001)$. Between the 2 groups, a decrease in BA-CA during treatment showed no significant difference. PAH at the end of treatment was significantly increased compared to baseline in both groups $(P<0.001)$. PAH at the end of treatment in the overweight/obesity group $(159.88 \pm 3.41 \mathrm{~cm})$ was similar to that of the normal weight group $(159.19 \pm 3.25 \mathrm{~cm})$. Comparing the 2 groups according to change in $\mathrm{BMI}$ after treatment, there were no differences in $\triangle \mathrm{PAH}, \triangle \mathrm{BA}-\mathrm{CA}$, and $\triangle$ height SDS for $\mathrm{BA}$.

Conclusion: GnRHa treatment in obese girls with CPP improved the height outcome and had similar results in normal weight CPP girls. Obesity might not affect the efficacy of GnRHa in girls with CPP.

Keywords: Central precocious puberty, Overweight, Obesity, Gonadotropinreleasing hormone agonist

\section{Introduction}

Central precocious puberty (CPP) is identified by the attainment of breast and testicle development prior to the age of 8 years in girls and 9 years in boys. Early development of secondary sexual characteristics are driven by the premature activation of the hypothalamicpituitary-gonadal axis ${ }^{1,2}$. Gonadotropin-releasing hormone analogs (GnRHa) treatment for CPP have been established as a gold-standard since the early $1980 \mathrm{~s}^{3)}$. GnRHa continuously stimulating the pituitary gonadotrophs leads it to desensitization and decreases the release of follicle stimulating hormone (FSH) and luteinizing hormone ( $\mathrm{LH})^{4}$. As such, GnRHa treatment postpones development of puberty and elongates the duration of growth and one maturation, thus, height potential is preserved ${ }^{3)}$.

Although the efficacy of GnRHa is well known, the long-term side effects remain controversial, especially in association with obesity and metabolic syndrome ${ }^{5,6)}$. Many previous 
studies have reported that GnRHa treatment is associated with changes in weight and body composition in precocious pubertal girls ${ }^{7}$. In obese or altered energy balance, metabolic modulators such as leptin and ghrelin regulate kisspeptin neuron ${ }^{8)}$. Then kisspeptin neurons stimulate GnRH secretion and gonadal steroid production. In the treatment of $\mathrm{GnRHa}$, obesity may affect gonadotropin suppression, and this feedback may affect the clinical finding as BA advancement and height outcome. However, few studies have reported the effect of obesity on the GnRHa treatment outcome.

Therefore, we aimed to investigate the effect and the clinical course of GnRHa treatment in obese girls compared to girls of normal weight with CPP.

\section{Materials and methods}

\section{Subjects}

We reviewed the medical records of 182 girls with CPP who had been treated with GnRHa in the pediatric endocrinology clinic of the Korea University Medical Center from July 2008 to March 2016.

The inclusion criteria for the diagnosis of CPP were (1) breast development before the chronological age (CA) of 8 year, (2) accelerated growth velocity, (3) advancement of bone age (BA) by 1 or more years above CA, and (4) peak LH concentration of $\geq 5 \mathrm{IU} / \mathrm{L}$ on the gonadotropin-releasing hormone stimulation test. Girls with known endocrine disease or any other chronic illness that might affect pubertal development and body composition were excluded. The patients were divided into 2 groups according to their BMI: overweight/obesity group, BMI $\geq 85$ th percentile for age and sex; normal weight group, BMI $\geq 3$ rd percentile and BMI $<85$ th percentile for age and sex using 2007 Korean national data ${ }^{9}$.

\section{Methods}

All patients were administered with leuprolide acetate $75-100 \mu \mathrm{g} / \mathrm{kg}$ depot injection every 4 weeks and regularly checked for height, weight, and degree of pubertal development. We evaluated the changes of height, weight, BMI, and sexual maturity in both groups at baseline, after 1 year, and at the end of GnRHa treatment. Height and BMI were expressed as the standard deviation score (SDS) for CA and BA. The SDS for height, weight, and BMI were calculated using the 2007 Korean National Growth Charts by LMS method ${ }^{9}$. BA was evaluated every 6 months by taking a radiograph of the left hand and determined using the Greulich-Pyle method ${ }^{10)}$. The difference between $\mathrm{BA}$ and $\mathrm{CA}$ (BA-CA) was evaluated to assess degree of BA advancement. Serum LH, FSH concentrations were measured by immunoradiometric assays. Using a GnRH stimulation test, the concentrations of LH and FSH at baseline, 30, 45, 60, and 90 minutes after the synthetic GnRH injection were measured. The predicted adult height (PAH) was calculated using the Bayley-Pinneau method ${ }^{11}$. We also compared the changes in BMI to both groups during GnRHa treatment.

The sexual maturity ratings were determined using the Marshall and Tanner method ${ }^{122}$. The midparental height (MPH) was calculated by subtracting $6.5 \mathrm{~cm}$ from the parents' mean height ${ }^{13)}$.

Of the total subjects, 46 girls were followed up after discontinuation of treatment and evaluated on reaching their near adult height. The near adult height was considered to be reached when $B A$ was around 13.5 years.

\section{Statistical analysis}

Data analysis was performed using IBM SPSS Statistics ver. 20.0 (IBM Co., Armonk, NY, USA). Comparison of the mean values of the 2 groups were performed by the Student $t$-test. The paired $t$-test was applied to compare the values at baseline and after GnRHa treatment in each group. Multiple linear regression analysis was performed to evaluate the several clinical factors influencing on changes in PAH. Data are represented as mean \pm standard deviation. Differences were considered to be statistically significant at $P<0.05$.

Table 1. Auxological characteristics of normal weight and overweight/obesity groups at baseline of gonadotropin-releasing hormone analogs treatment

\begin{tabular}{lccc}
\hline Characteristic & $\begin{array}{c}\text { Normal } \\
(\mathrm{n}=108)\end{array}$ & $\begin{array}{c}\text { Overweight/obesity } \\
(\mathrm{n}=74)\end{array}$ & P-value \\
\hline CA (yr) & $8.55 \pm 0.47$ & $8.47 \pm 0.49$ & 0.226 \\
BA (yr) & $10.21 \pm 0.66$ & $10.28 \pm 0.71$ & 0.492 \\
Mid parental height (cm) & $160.01 \pm 3.48$ & $159.16 \pm 3.61$ & 0.114 \\
Predicted adult height (cm) & $157.58 \pm 2.82$ & $158.02 \pm 2.66$ & 0.297 \\
Tanner stage & & & $0.006^{*}$ \\
B2 & $76(70.4)$ & $36(48.6)$ & \\
B3 & $29(26.9)$ & $35(47.3)$ & \\
B4 & $3(2.8)$ & $3(4.1)$ & \\
Height (cm) & $135.27 \pm 5.54$ & $136.03 \pm 5.08$ & 0.350 \\
Height-SDS for CA & $1.14 \pm 0.84$ & $1.35 \pm 0.70$ & 0.080 \\
Height-SDS for BA & $-0.47 \pm 0.50$ & $-0.42 \pm 0.48$ & 0.488 \\
Weight (kg) & $30.95 \pm 3.69$ & $38.60 \pm 4.19$ & $<0.001^{*}$ \\
Weight-SDS & $1.82 \pm 0.61$ & $1.69 \pm 0.42$ & $<0.001^{*}$ \\
BMI (kg/m $\left.{ }^{2}\right)$ & $16.87 \pm 1.28$ & $20.81 \pm 1.36$ & $<0.001^{*}$ \\
BMI-SDS & $0.08 \pm 0.60$ & $1.55 \pm 0.36$ & $<0.001^{*}$ \\
Basal LH & $0.72 \pm 0.73$ & $0.74 \pm 0.63$ & 0.870 \\
Peak LH & $16.37 \pm 12.97$ & $12.53 \pm 11.79$ & $0.043^{*}$ \\
Basal FSH & $3.14 \pm 2.44$ & $2.99 \pm 2.34$ & 0.697 \\
Peak FSH & $16.20 \pm 8.38$ & $15.65 \pm 7.89$ & 0.658 \\
\hline Values & & & \\
\hline
\end{tabular}

Values are presented as mean \pm standard deviation or number (\%). CA, chronological age; BA, bone age; SDS, standard deviation score; BMI, body mass index; LH, luteinizing hormone; FSH, follicle stimulating hormone.

${ }^{*} P<0.05$, statistically significant differences. 


\section{Ethics Statement}

This study was approved by the Institutional Review Board of Korea University Anam Hospital (approval number: ED16208) and informed consent was waived by the IRB.

\section{Results}

\section{Comparison of clinical parameters of the normal weight and overweight/obesity groups at baseline}

One hundred eighty-two female patients were included in the study: 108 patients in the normal weight group and 74 patients in the overweight/obesity group. The auxological characteristics of both groups before and after GnRHa treatment are described in Table 1. The mean CA and BA ate the start of GnRHa

Table 2. Auxological characteristics of normal weight and overweight/obesity groups at the end of gonadotropin-releasing hormone analogs treatment

\begin{tabular}{|c|c|c|c|}
\hline Characteristic & $\begin{array}{l}\text { Normal } \\
(n=108)\end{array}$ & $\begin{array}{l}\text { Overweight/obesity } \\
\qquad(n=74)\end{array}$ & $P$-value \\
\hline CA (yr) & $10.98 \pm 0.36$ & $10.89 \pm 0.42$ & 0.134 \\
\hline BA (yr) & $11.77 \pm 0.44$ & $11.94 \pm 0.38$ & $0.005^{*}$ \\
\hline$B A-C A(y r)$ & $-0.78 \pm 0.50$ & $-1.05 \pm 0.55$ & $0.001^{*}$ \\
\hline Treatment duration (yr) & $2.43 \pm 0.60$ & $2.45 \pm 0.59$ & 0.787 \\
\hline PAH (cm) & $159.19 \pm 3.25$ & $159.88 \pm 3.41$ & 0.169 \\
\hline$\triangle \mathrm{PAH}(\mathrm{cm})$ & $1.61 \pm 2.87$ & $1.86 \pm 3.01$ & 0.577 \\
\hline Height (cm) & $148.31 \pm 4.90$ & $150.34 \pm 4.40$ & $0.011^{*}$ \\
\hline Height-SDS for CA & $0.68 \pm 0.78$ & $1.00 \pm 0.75$ & $0.007^{*}$ \\
\hline Height-SDS for BA & $-0.04 \pm 0.61$ & $0.08 \pm 0.62$ & 0.204 \\
\hline $\mathrm{BMI}\left(\mathrm{kg} / \mathrm{m}^{2}\right)$ & $19.25 \pm 1.88$ & $23.22 \pm 1.71$ & $<0.001^{*}$ \\
\hline BMI-SDS & $0.40 \pm 0.64$ & $1.55 \pm 0.42$ & $<0.001^{*}$ \\
\hline
\end{tabular}

Values are presented as mean \pm standard deviation.

CA, chronological age; BA, bone age; PAH, predicted adult height; SDS, standard deviation score; BMI, body mass index.

${ }^{*} P<0.05$, statistically significant differences.

(A)

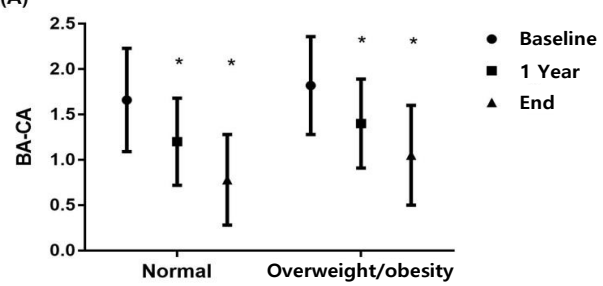

(C)

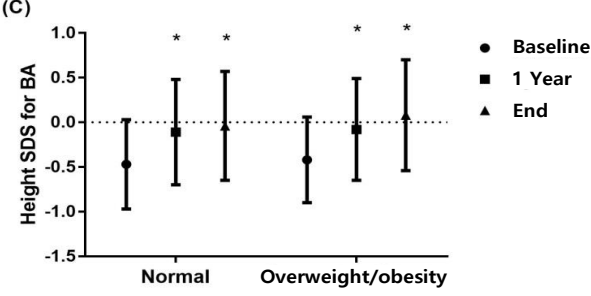

treatment were similar in both groups. The MPH, PAH and height SDS were not significantly different between the 2 groups. The mean BMIs of the normal weight group and the overweight/obese group were $16.87 \pm 1.28 \mathrm{~kg} / \mathrm{m}^{2}$ and $20.81 \pm 1.36$ $\mathrm{kg} / \mathrm{m}^{2}$, respectively $(P<0.001)$. The BMI SDS were $0.08 \pm 0.60$ and $1.55 \pm 0.36$ in each group $(P<0.001)$.

\section{Comparison of clinical parameters of the normal weight and overweight/obesity groups at the end of the treatment}

All patients received GnRHa treatment for more than 1 year. The 2 groups had a similar mean treatment duration $(2.43 \pm 0.60$ years vs. $2.45 \pm 0.59$ years, $P=0.787$ ) (Table 2). At the end of treatment, The CA was similar between the groups after the last GnRHa treatment, whereas the BA was more advanced and the height SDS for CA was higher in the overweight/obesity group. A significant decrease in BA-CA during GnRHa treatment was similar between groups. The height SDS for BA and PAH revealed similar results for both groups.

\section{Changes in clinical parameters on growth outcome during $\mathrm{GnRH}$ a treatment}

We followed up parameters indicating a treatment effect at 1 year and at the finish on GnRHa treatment (Fig. 1). In both groups, the BA-CA significantly and gradually decreased over the treatment period compared with baseline. The height SDS for CA significantly decreased and the height SDS for $\mathrm{BA}$ increased during treatment in both groups, respectively. At the end of treatment, PAH in both groups was significantly increased compared with baseline PAH. The mean PAH increased by $1.61 \pm 2.87 \mathrm{~cm}$ in the normal weight group and by $1.86 \pm 3.01 \mathrm{~cm}$ in the overweight/obesity group, before and after treatment (all $P<0.001$ ). During the treatment of GnRHa, changes in parameters were compared between the 2 groups (Table 3). The change in height SDS or BA and BA-CA after 1 year and end of the treatment between both groups are not

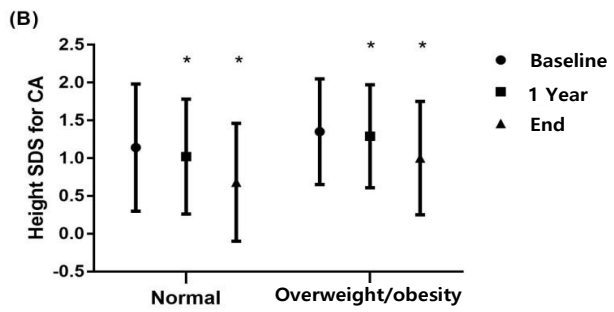

Fig. 1. Changes in treatment-effect parameters during gonadotropin-releasing hormone agonist treatment. BA-CA (A), height SDS for CA (B), and height SDS for BA (C). BA, bone age; $C A$, chronological age; $B A-C A$, difference between $B A$ and $C A$; SDS, standard deviation score. ${ }^{*} P<0.001$ compared to baseline of treatment. 
different.

\section{Correlation between the auxological factors and the $\triangle \mathrm{PAH}$ at the end of treatment}

Multiple regression analysis was performed to assess the factors influencing $\triangle \mathrm{PAH}$ at the end of treatment (Table 4). In both groups, $\triangle \mathrm{PAH}$ was statistically correlated with baseline BA, baseline height SDS for BA and growth velocity during the 1st year. Baseline BMI for CA was not significantly associated with $\triangle \mathrm{PAH}$ at the end of treatment in both groups.

\section{Changes in BMl during GnRHa treatment}

Before and after GnRHa treatment, the mean BMI SDS in the normal weight group significantly increased (Fig. 2). The mean BMI SDS also increased significantly 0.27 at 1 year and 0.40 at the end of treatment, compared to baseline (all $P<0.001$ ). However, mean BMI-SDS in overweight/obesity group did not show significant change during this period. At 1 year and the end of treatment, mean BMI SDS in the overweight/obesity group was 1.51 and $1.55(P=0.201$ and $P=0.994$, respectively).

\section{Comparison of treatment efficacy according to change in BMl during $\mathrm{GnRHa}$ treatment}

Of the total 182 patients, the BMI SDS was increased in 120

Table 3. Comparison of clinical parameters between normal weight and overweight/obesity groups during gonadotropinreleasing hormone analogs treatment

\begin{tabular}{|c|c|c|c|}
\hline Variable & $\begin{array}{l}\text { Normal } \\
(n=108)\end{array}$ & $\begin{array}{l}\text { Overweight/obesity } \\
\qquad(n=74)\end{array}$ & $P$-value \\
\hline$\triangle$ Height-SDS for CA, $1 \mathrm{yr}$ & $-0.12 \pm 0.29$ & $-0.06 \pm 0.15$ & 0.088 \\
\hline$\triangle$ Height-SDS for CA, end & $-0.46 \pm 0.30$ & $-0.35 \pm 0.26$ & $0.012^{*}$ \\
\hline$\triangle$ Height-SDS for BA, 1yr & $0.36 \pm 0.42$ & $0.35 \pm 0.40$ & 0.815 \\
\hline$\triangle$ Height-SDS for BA, end & $0.43 \pm 0.49$ & $0.50 \pm 0.46$ & 0.356 \\
\hline$\triangle \mathrm{BA}-\mathrm{CA}, 1 \mathrm{yr}$ & $-0.46 \pm 0.41$ & $-0.42 \pm 0.39$ & 0.482 \\
\hline$\triangle B A-C A$, end & $-0.87 \pm 0.52$ & $-0.77 \pm 0.45$ & 0.163 \\
\hline$\triangle \mathrm{BMI}-\mathrm{SDS}, 1 \mathrm{yr}$ & $0.19 \pm 0.38$ & $-0.04 \pm 0.28$ & $<0.001^{*}$ \\
\hline$\triangle \mathrm{BMI}-\mathrm{SDS}$, end & $0.32 \pm 0.46$ & $0.00 \pm 0.37$ & $<0.001^{*}$ \\
\hline
\end{tabular}

Values are presented as mean \pm standard deviation.

SDS, standard deviation score; CA, chronological age; BA, bone age; $B A-C A$, difference between $B A$ and $C A$; $B M I$, body mass index. patients $(65.9 \%)$ at the end of treatment (Table 5). The baseline BMI SDS of the increased BMI SDS group was lower than that of the decreased BMI SDS group $(P<0.001)$. There were no significant difference in $\triangle \mathrm{PAH}, \triangle \mathrm{BA}-\mathrm{CA}, \triangle$ height SDS for $\mathrm{CA}$, $\triangle$ height SDS for BA between the 2 groups.

\section{Follow-up after discontinuation of GnRHa treatment}

After discontinuation of treatment, the near adult height of 46 girls, reaching approximately 13.5 years of BA, was subsequently

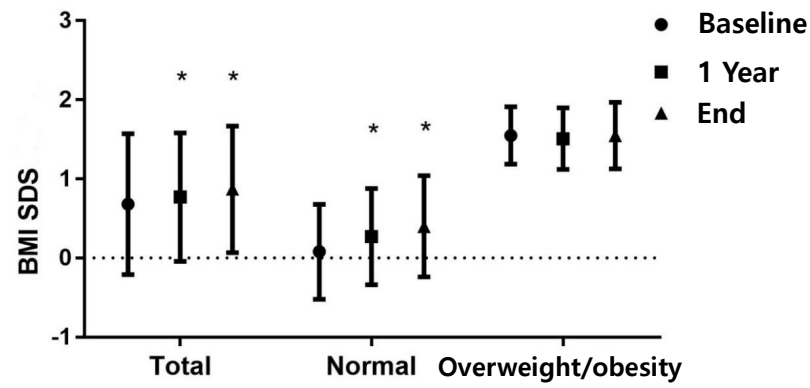

Fig. 2. Changes in the BMI SDS during gonadotropin-releasing hormone agonist treatment. BMI, body mass index; SDS, standard deviation score. ${ }^{*} P<0.001$ compared to baseline of treatment.

Table 5. Comparison of 2 subgroups according to change in BMI during gonadotropin-releasing hormone analogs treatment

\begin{tabular}{|c|c|c|c|}
\hline Variable & $\begin{array}{c}\triangle B M I-S D S>0 \\
(n=120)\end{array}$ & $\begin{array}{c}\triangle B M I-S D S<0 \\
(n=62)\end{array}$ & $P$-value \\
\hline Baseline BMI-SDS & $0.50 \pm 0.86$ & $1.03 \pm 0.85$ & $<0.001$ \\
\hline End BMI-SDS & $0.94 \pm 0.76$ & $0.73 \pm 0.84$ & 0.087 \\
\hline$\triangle \mathrm{BMI}-\mathrm{SDS}$ & $0.45 \pm 0.32$ & $-0.30 \pm 0.21$ & $<0.001$ \\
\hline Baseline PAH & $157.73 \pm 2.72$ & $157.82 \pm 2.86$ & 0.825 \\
\hline$\triangle \mathrm{PAH}$ & $1.80 \pm 2.78$ & $1.54 \pm 3.20$ & 0.572 \\
\hline Baseline BA-CA & $1.74 \pm 0.52$ & $1.69 \pm 0.43$ & 0.617 \\
\hline$\triangle B A-C A$ & $-0.81 \pm 0.50$ & $-0.87 \pm 0.49$ & 0.507 \\
\hline Baseline height-SDS for CA & $1.27 \pm 0.77$ & $1.16 \pm 0.83$ & 0.377 \\
\hline$\triangle$ Height-SDS for CA & $-0.41 \pm 0.25$ & $-0.44 \pm 0.34$ & 0.451 \\
\hline Baseline height-SDS for BA & $-0.43 \pm 0.49$ & $-0.50 \pm 0.49$ & 0.425 \\
\hline$\triangle$ Height-SDS for BA & $0.47 \pm 0.45$ & $0.45 \pm 0.52$ & 0.811 \\
\hline
\end{tabular}

Values are presented as mean \pm standard deviation.

$\mathrm{BMI}$, body mass index; SDS, standard deviation score; $\mathrm{PAH}$, predicted adult height; $\mathrm{BA}-\mathrm{CA}$, difference between $\mathrm{BA}$ and $\mathrm{CA}$; $\mathrm{CA}$, chronological age; $\mathrm{BA}$, bone age.

Table 4. A multiple regression analysis on $\triangle \mathrm{PAH}$ according to obesity groups

\begin{tabular}{|c|c|c|c|c|c|c|c|c|c|}
\hline \multirow{2}{*}{ Variable } & \multicolumn{3}{|c|}{ Total } & \multicolumn{3}{|c|}{ Normal } & \multicolumn{3}{|c|}{ Overweight/obesity } \\
\hline & Coefficient & SE & $P$-value & Coefficient & SE & $P$-value & Coefficient & SE & $P$-value \\
\hline Baseline BA & 1.265 & 0.275 & $<0.001$ & 1.315 & 0.374 & 0.001 & 1.187 & 0.423 & 0.007 \\
\hline Baseline height-SDS for BA & 4.411 & 0.932 & $<0.001$ & 3.553 & 1.163 & 0.003 & 5.614 & 1.635 & 0.001 \\
\hline Growth velocity during 1 st year & 68.982 & 15.449 & $<0.001$ & 62.201 & 18.233 & 0.001 & 82.757 & 31.659 & 0.011 \\
\hline Baseline BMI-SDS & 0.141 & 0.212 & 0.507 & 0.342 & 0.402 & 0.397 & -0.621 & 0.856 & 0.471 \\
\hline
\end{tabular}

Total group: $R^{2}=0.317, P<0.001$; normal group: $R^{2}=0.316, P<0.001$; overweight/obesity group; $R^{2}=0.343, P<0.001$.

$\mathrm{PAH}$, predicted adult height; $\mathrm{SE}$, standard error; $\mathrm{BA}$, bone age; SDS, standard deviation score; BMI, body mass index. 
Table 6. Final data of $\mathbf{4 6}$ girls after discontinuation of gonadotropin-releasing hormone analogs treatment

\begin{tabular}{|c|c|c|c|}
\hline Variable & $\begin{array}{l}\text { Normal } \\
(n=29)\end{array}$ & $\begin{array}{l}\text { Overweight/obesity } \\
\qquad(n=17)\end{array}$ & $P$-value \\
\hline CA (yr) & $12.85 \pm 0.88$ & $12.62 \pm 1.23$ & 0.480 \\
\hline$B A(y r)$ & $13.91 \pm 0.70$ & $14.06 \pm 0.90$ & 0.544 \\
\hline Midparental height (cm) & $160.01 \pm 3.48$ & $159.16 \pm 3.61$ & 0.114 \\
\hline Baseline PAH (cm) & $157.91 \pm 3.08$ & $158.31 \pm 2.43$ & 0.645 \\
\hline Near adult height $(\mathrm{cm})$ & $160.17 \pm 3.72$ & $161.04 \pm 3.91$ & 0.456 \\
\hline Baseline BMI-SDS & $0.09 \pm 0.68$ & $1.42 \pm 0.50$ & $<0.001^{*}$ \\
\hline$\triangle \mathrm{BMI}-\mathrm{SDS}, 1 \mathrm{yr}$ & $0.09 \pm 0.43$ & $-0.12 \pm 0.30$ & 0.084 \\
\hline$\triangle B M I-S D S$, end & $0.40 \pm 0.56$ & $-0.06 \pm 0.36$ & $0.003^{*}$ \\
\hline
\end{tabular}

Values are presented as mean \pm standard deviation.

$\mathrm{CA}$, chronological age; $\mathrm{BA}$, bone age; $\mathrm{PAH}$, predicted adult height; $\mathrm{BMI}$, body mass index; SDS, standard deviation score.

evaluated (Table 6). The near adult height of 29 girls in the normal weight group and of 17 girls in the overweight/obesity group were not significantly different $(160.17 \pm 3.72 \mathrm{~cm}$ and $161.04 \pm 3.91 \mathrm{~cm}$, respectively, $P=0.569)$. Their initial $\mathrm{PAH}$ was $157.91 \pm 3.08 \mathrm{~cm}$ and $158.31 \pm 2.43 \mathrm{~cm}$, respectively. The near adult height of 2 groups was significantly greater than their initial PAH $(2.26 \pm 3.70 \mathrm{~cm}$ vs. $2.72 \pm 3.85 \mathrm{~cm}$, respectively, $P<0.001)$. Normal weight group revealed more increase in BMISDS compared to those of overweight/obesity group.

\section{Discussion}

In the current study we compared the clinical course and treatment effect between normal weight and overweight/obese girls during GnRHa treatment for CPP and GnRHa treatment improved the height outcome and delayed progression of bone maturation in both normal weight girls and obese girls with CPP. GnRHa treatment efficacy was not affected by the obesity in female CPP patients. The BMI SDS significantly increased only in normal weight female CPP patients during long-term GnRHa treatment.

The number of CPP patients is increasing worldwide, and in Korea $^{14,15)}$. As the report of the Health Insurance Review and Assessment Service, CPP patients increased annually about 44.4\% from 2006 to 2010 in Korea ${ }^{16)}$. In addition, a marked increase of obesity prevalence in childhood has been observed around the world ${ }^{17,18)}$. Many studies have been performed to investigate the association between precocious puberty and obesity ${ }^{19}$. A Swedish longitudinal study reported that an increase of BMI in childhood was associated with an earlier timing of pubertal onset, by as much as 0.7 years in girls and 0.6 years in boys ${ }^{20)}$. Since recent reports have primarily focused on whether GnRHa treatment has increased BMI or not, we investigated the clinical parameters to evaluate whether the obesity affects the treatment outcome in CPP girls.

In this study, the overall course of treatment in both groups was similar. We found that BA-CA in both groups significantly decreased during follow-up. It means that GnRHa also worked well in postponing bone maturity in the overweight/obesity group. Both groups similarly revealed distinct improvement of PAH and height SDS for BA. At the end of treatment, PAH increased $1.61 \pm 2.87 \mathrm{~cm}$ vs. $1.86 \pm 3.01 \mathrm{~cm}$ in the normal weight and overweight/obese groups, respectively, compared to the beginning of treatment. Near adult height of 46 patients showed height gain of $2.26 \pm 3.70 \mathrm{~cm}$ in the normal weight group and $2.72 \pm 3.85 \mathrm{~cm}$ in the overweight/obese group, respectively, compared to their baseline PAH. Near adult height was comparable to their MPH, although gain of height is smaller than that of previous other studies. Thus, it is considered that GnRHa treatment can be effective in height outcome in our study. According to previous study about GnRHa treatment effects in obese CPP girls, Yoon et al. ${ }^{21)}$ reported that PAH SDS significantly increased in overweight/obesity group compared to in the normal weight group, and BA-CA similarly decreased in both groups during 1-year of GnRHa treatment in CPP girls.

We performed a multiple regression analysis and compared the factors predicting $\triangle \mathrm{PAH}$ in both groups, respectively. Our results suggest that greater baseline BA and height SDS for BA and growth velocity for the first year of treatment indicate good growth outcomes, regardless of the treatment group. However, body weight and BMI did not exhibit any statistical correlation with PAH at the end of treatment. Obesity did not contribute significantly to the height outcome. In previous other studies, Partsch et al. ${ }^{22)}$ reported that initial BA advancement and treatment duration were factors that explained $68 \%$ of height gain. Other studies found that MPH, CA, pretreatment height, height at the end of treatment, and growth rate during treatment were factors influencing near final height ${ }^{23,24)}$.

Several previous studies have evaluated alterations in BMI before and after GnRHa treatment in CPP. Whether GnRHa treatment affects BMI and aggravates obesity remain controversial ${ }^{25)}$. Shiasi Arani and Heidari ${ }^{26)}$ reported that girls treated for CPP revealed no change in BMI compared with girls not treated for CPP, during 1 year of follow up. In contrast, Paterson et al. ${ }^{27)}$ reported a marked increase in mean BMI SDS after treatment from 0.93 to 1.2 in girls with early puberty and CPP. On the other hand in our study, BMI SDS significantly increased in the normal weight group only during $\mathrm{GnRHa}$ treatment. The reasons explaining an increase in BMI SDS in normal weight group are unclear. Paterson et al. ${ }^{27)}$ found that the mean BMI SDS returned to the pretreatment state 3 years after finishing GnRHa treatment course, suggesting that the weight increase was a transient phenomenon. Wolters et al. ${ }^{28)}$ explained the beneficial effect of GnRHa on weight status by reducing sex hormones that lead to weight gain through increase in body fat and muscle mass during GnRHa treatment. However, this is insufficient to account for the difference in the impact of GnRHa on weight status between overweight and normal weight children. In our study, 19 of the normal weight groups showed increased BMI and they were turned into overweight or obese at the end of treatment, whereas, 89 patients maintained normal weight persistently. Patients who turned into overweight/obesity revealed higher BMI SDS at baseline and more increase in BMI SDS compared to patients with 
normal BMI SDS at the end of treatment (0.51 vs. $-0.01, P<0.001$ and 0.74 vs. $0.23, P<0.001$, respectively). On the other hand, overweight/obese patients at baseline showed a tendency to maintain their BMI SDS, and this finding is consistent with that in previous studies ${ }^{28,29)}$. Pich et al. ${ }^{30)}$ reported that obese patients may have tendency to recognize their obese status and modify risk factors such as diet, sleep and physical activity. However, our study cannot investigate these factors. A prospective further study is warranted to confirm the tendency.

The strength of our study is that all subjects were had CPP, except for those in early puberty and that they were separated into 2 groups; namely overweight and normal weight girls. However, in our retrospective study, there were some limitations. There were no clinical measures of body adiposity, such as waist circumference, skinfold thickness or dual-energy $\mathrm{x}$-ray absorptiometry. Although BMI is a valid tool to determine obesity, it has limitations as an indirect measure of fat mass. A long-term follow-up following discontinuation of GnRHa treatment is lacking in our study. To confirm the effects of obesity on the treatment outcome, additional analysis of the final height, BMI SDS and menarche age is required.

In conclusion, obese girls with CPP had an improved height outcome similar to normal weight girls during GnRHa treatment. Obesity may not affect the efficacy of GnRHa in girls with CPP.

\section{Conflict of interest}

No potential conflict of interest relevant to this article was reported.

\section{References}

1. Parent AS, Teilmann G, Juul A, Skakkebaek NE, Toppari J, Bourguignon JP. The timing of normal puberty and the age limits of sexual precocity: variations around the world, secular trends, and changes after migration. Endocr Rev 2003;24:668-93.

2. Lee PA. Central precocious puberty. An overview of diagnosis, treatment, and outcome. Endocrinol Metab Clin North Am 1999;28:901-18.

3. Partsch CJ, Heger S, Sippell WG. Management and outcome of central precocious puberty. Clin Endocrinol (Oxf) 2002;56:129-48.

4. Lahlou N, Carel JC, Chaussain JL, Roger M. Pharmacokinetics and pharmacodynamics of GnRH agonists: clinical implications in pediatrics. J Pediatr Endocrinol Metab 2000;13 Suppl 1:723-37.

5. Kim EY. Long-term effects of gonadotropin-releasing hormone analogs in girls with central precocious puberty. Korean J Pediatr 2015;58:1-7.

6. Latronico AC, Brito VN, Carel JC. Causes, diagnosis, and treatment of central precocious puberty. Lancet Diabetes Endocrinol 2016;4:265-74.
7. Arrigo T, De Luca F, Antoniazzi F, Galluzzi F, Segni M, Rosano M, et al. Reduction of baseline body mass index under gonadotropin-suppressive therapy in girls with idiopathic precocious puberty. Eur J Endocrinol 2004;150:533-7.

8. De Bond JA, Smith JT. Kisspeptin and energy balance in reproduction. Reproduction 2014;147:R53-63.

9. Moon JS, Lee SY, Nam CM, Choi JM, Choe BK, Seo JW, et al. 2007 Korean National Growth Charts: review of developmental process and an outlook. Korean J Pediatr 2008;51:1-25.

10. Greulich W, Pyle S. Radiologic atlas of skeletal development of the hand and wrist. 2nd ed. Redwood City (CA): Stanford University Press, 1959.

11. Bayley N, Pinneau SR. Tables for predicting adult height from skeletal age: revised for use with the Greulich-Pyle hand standards. J Pediatr 1952;40:423-41.

12. Marshall WA, Tanner JM. Variations in pattern of pubertal changes in girls. Arch Dis Child 1969;44:291-303.

13. Tanner JM, Goldstein H, Whitehouse RH. Standards for children's height at ages 2-9 years allowing for heights of parents. Arch Dis Child 1970;45:755-62.

14. Mogensen SS, Aksglaede L, Mouritsen A, Sørensen K, Main KM, Gideon P, et al. Diagnostic work-up of 449 consecutive girls who were referred to be evaluated for precocious puberty. J Clin Endocrinol Metab 2011;96:1393-401.

15. Kim HK, Kee SJ, Seo JY, Yang EM, Chae HJ, Kim CJ. Gonadotropin-releasing hormone stimulation test for precocious puberty. Korean J Lab Med 2011;31:244-9.

16. Health Insurance Review \& Assessment Service. The early detection of precocious puberty is important [Internet]. Seoul: Health Insurance Review \& Assessment Service; c2013 [cited 2016 Sep 14]. Available from: http://www.hira. or.kr.

17. Yang L, Colditz GA. Prevalence of overweight and obesity in the United States, 2007-2012. JAMA Intern Med 2015;175:1412-3.

18. Ogden CL, Carroll MD, Curtin LR, McDowell MA, Tabak CJ, Flegal KM. Prevalence of overweight and obesity in the United States, 1999-2004. JAMA 2006;295:1549-55.

19. Heger S, Körner A, Meigen C, Gausche R, Keller A, Keller E, et al. Impact of weight status on the onset and parameters of puberty: analysis of three representative cohorts from central Europe. J Pediatr Endocrinol Metab 2008;21:86577.

20. He Q, Karlberg J. Bmi in childhood and its association with height gain, timing of puberty, and final height. Pediatr Res 2001;49:244-51.

21. Yoon JY, Kang MJ, Kim SY, Seo JY, Yang SW, Lee YA, et al. The relationship between initial body mass index and body mass index after one year of gonadotropin-releasing hormone agonist therapy in idiopathic true precocious puberty girls. J Korean Soc Pediatr Endocrinol 2011;16:16571.

22. Partsch CJ, Heger S, Sippell WG. Treatment of central 
precocious puberty: lessons from a 15 years prospective trial. German Decapeptyl Study Group. J Pediatr Endocrinol Metab 2000;13 Suppl 1:747-58.

23. Arrigo T, Cisternino M, Galluzzi F, Bertelloni S, Pasquino AM, Antoniazzi F, et al. Analysis of the factors affecting auxological response to GnRH agonist treatment and final height outcome in girls with idiopathic central precocious puberty. Eur J Endocrinol 1999;141:140-4.

24. Gyon Y, Yun YJ, Kim YD, Han HS. Age at menarche and near final height after treatment with gonadotropinreleasing hormone agonist alone or combined with growth hormone in Korean girls with central precocious puberty. Clin Pediatr Endocrinol 2015;24:175-83.

25. Heger S, Partsch CJ, Sippell WG. Long-term outcome after depot gonadotropin-releasing hormone agonist treatment of central precocious puberty: final height, body proportions, body composition, bone mineral density, and reproductive function. J Clin Endocrinol Metab 1999;84:4583-90.
26. Shiasi Arani K, Heidari F. Gonadotropin-releasing hormone agonist therapy and obesity in girls. Int J Endocrinol Metab 2015; 13:e23085.

27. Paterson WF, McNeill E, Young D, Donaldson MD. Auxological outcome and time to menarche following longacting goserelin therapy in girls with central precocious or early puberty. Clin Endocrinol (Oxf) 2004;61:626-34.

28. Wolters B, Lass N, Reinehr T. Treatment with gonadotropinreleasing hormone analogues: different impact on body weight in normal-weight and overweight children. Horm Res Paediatr 2012;78:304-11.

29. Lee HS, Yoon JS, Roh JK, Hwang JS. Changes in body mass index during gonadotropin-releasing hormone agonist treatment for central precocious puberty and early puberty. Endocrine 2016;54:497-503.

30. Pich J, Bibiloni Mdel M, Pons A, Tur JA. Weight selfregulation process in adolescence: the relationship between control weight attitudes, behaviors, and body weight status. Front Nutr 2015;2:14. 